\title{
Contando o conto de Zita as estórias dos servos sagrados e a história dos servos*
}

\author{
Telling Zita's Tale \\ holy servants' stories and servants' history**
}

\author{
Rafaella SARTI \\ Universidade de Urbino- Itália \\ Facoltà di Lettere e Filosofia \\ Via S.Lucia, 6 - 61029 Urbino - Itália \\ Raffaella.sarti@uniurb.it
}

RESUMO Este artigo se concentra em um tipo particular de narrativa sobre servos, ${ }^{1}$ as Vidas de servos sagrados. Em particular, foca a vida de uma santa medieval, Zita de Lucca, que viveu no século XIV. Mostra como sua

* Artigo recebido em: 28/05/2007. Aprovado em: 15/08/2007.

(O paper Servants speaking about themselves: the members of the Bolognese Confraternity of San Vitale $-17^{\text {th }}-19^{\text {th }}$ centuries, que eu apresentei no seminário Narratives of the servant - Florença 17-18 de março de 2000 - é parte de um artigo que foi publicado, intitulado SARTI, Rafaella. The true servant. self-definition of male domestic in an Italian city (Bologna, $17^{\text {th }}-19^{\text {th }}$ centuries). The history of the family, vol.10, $n^{\circ} .4,2005$, número especial Domestic Servants in Comparative Perspective, editado por Antoinette Fauve-Chamoux e Richard Wall. Eu também analisei a história da confraria Bolognese de San Vitale em um artigo italiano: SARTI, Raffaella. L'Università dei servitori di Bologna, sec. XVII-XIX. In GUENZI, Alberto, MASSA, Paola, MOIOLI, Angelo. (eds.) Corporazioni e gruppi professionali nell'Italia Modema. Milano: Angeli, 1999, p.717-754. Este artigo que ora se publica é uma versão revisada do paper Holy and Profane Aspects of the Servant que apresentei no seminário organizado por Regina Schulte, na EUI, no dia 11 de novembro de 1999. As seções 2-11 são uma tradução parcial, com algumas mudanças, de um artigo que publiquei em 1994: SARTI, Raffaella. Zita, serva e santa. Um modello da imitare? In: BARONE, Giulia, CAFFIERO, Marina, SCORZA BARCELLONA, Francesco. (eds.) Modelli di santità e modelli di comportamento. Contrasti, intersezioni, complementarità. Torino: Rosenberg \& Sellier, 1994, p.307-359. Sou grata ao editor e aos editores que me permitiram traduzir partes do texto).

** Tradução de Clara Furtado Lins.

1 A palavra empregada pela autora foi servants. Durante a tradução empreguei alternadamente os termos servo, serviçal ou criado. Segundo o dicionário Aurélio, a palavra servo tanto pode significar 1) aquele indivíduo, na época moderna, cujo serviço estava adstrito à gleba, quanto 2) criado, servidor, servente ou serviçal. Em geral empreguei o termo com esse segundo sentido. FERREIRA, Aurélio Buarque de Holanda. Servo. In: Novo Aurélio, o dicionário da língua portuguesa, século XXI. Rio de Janeiro: Nova Fronteira, 1999, col.2, p.1846. 
imagem foi modificada com o objetivo de transformá-la em um modelo a ser imitado, especialmente pelos servos, entre os séculos XVI e XVIII. Descreve a estratégia elaborada pela Igreja Católica, nos séculos XVI e XVII, para impedir a disseminação da Reforma Protestante, dando atenção particular ao papel dado à hagiografia. Aponta como a história de Zita pode se ajustar à política de restauração moral e religiosa buscada pela Igreja Católica entre os séculos XIX e XX. Analisa como a mesma história foi contada de várias maneiras em diversos contextos culturais e sociais e por autores com objetivos diferentes. Nesse sentido, após analisar a "história das histórias de Zita", o artigo chama a atenção para as transformações socioeconômicas por que passaram os serviços domésticos, particularmente no que diz respeito ao aumento das taxas de feminilidade entre os mesmos, tentando entender as implicações e conseqüências mais gerais desse aumento à luz da História Social e de Gênero.

Palavras-chave Hagiografia, santa Zita de Lucca, Reforma Protestante, santos

ABSTRACT This article aims to discuss on a particular type of narrative about servants, the Lifes of holy servants. In particular it will focus on the Lives of a medieval saint, Zita of Lucca, that lived in the $14^{\text {th }}$ century. It will show how her image was modified in order to transform it into a model to be imitated, special by servants, between the $16^{\text {th }}$ and the $18^{\text {th }}$ centuries. It will also describe the strategy elaborated by the Catholic Church in the $16^{\text {th }}$ and the $17^{\text {th }}$ centuries in order to reform its body and in order to arrest the spreading of the Protestant Reformation, paying particular attention to the role attributed to hagiography. Zita's story could suit the police of moral and religious restoration pursued by the Catholic Church in the $19^{\text {th }}$ and part of the $20^{\text {th }}$ centuries. It will analyze how the same story has been told differently in different cultural and social contexts and by authors who were pursuing different aims. After analyze the "story of Zita's stories", it will discuss the socio-economic transformations of domestic service, in particular on its feminization, trying to understand the more general implications and consequences of feminization with regard to social and gender history.

Key words Hagiography, saint Zita of Lucca, Protestant Reform, saints

\section{Introdução}

Contar estórias - estórias verdadeiras ou imaginárias - é uma atividade da vida e da experiência humana. Na cultura ocidental, uma grande quantidade de narrativas também fala dos servos, criados e serviçais, desde os dialéticos mestre e criado de Hegel, até a biografia de Proust feita por 
sua governanta Céleste Albaret, para citar apenas dois. ${ }^{2}$ De fato, existem narrativas que apresentam servos altamente estereotipados, como é o caso de muitas peças teatrais. ${ }^{3}$ Há narrativas que lidam com servos metafóricos, como, por exemplo, a biografia de várias pessoas sagradas descritas como "servos de Deus" ou o Novo Testamento, que conta a história de Cristo, que veio ao mundo não para ser servido mas para servir. Finalmente, há narrativas que falam de servos verdadeiros, variando entre biografias ou autobiografias de criados domésticos, a livros sobre os criados domésticos escritos por historiadores. ${ }^{4}$

Essa grande variedade de narrativas depende, em primeiro lugar, do fato de que durante muito tempo o termo "servo" foi (muito mais do que atualmente) um termo polissêmico, usado em referência a vários tipos de pessoas. O mundo dos servos, criados e domésticos foi durante séculos uma área com limites incertos. Um verdadeiro universo, como eu escrevi em outro lugar. ${ }^{5}$ Nicolò Vito di Gozze, autor de um tratado sobre o cuidado familiar (1589), lembra por exemplo que os servos são "variados e de diferentes tipos": "servos por natureza," "servos por lei", "servos por remuneração", servos "por virtude ou prazer". Dentro de "servos por natureza" ele inclui os "bárbaros e pessoas incivilizadas" que moravam no interior. Os "servos por lei" são os escravos. Os "servos por remuneração" são pessoas livres que se colocavam a serviço de um mestre: entre eles alguns servem apenas em troca de casa e roupa; outros além disso recebem um salário; outros, ainda, trabalham "por remuneração apenas", suprindo suas necessidades sozinhos. Há finalmente aqueles que servem não "por dinheiro ou compul-

2 BURGESS, J. Peter. In The Service of Narrative: master and servant in the Philosophy of Hegel; DIEHL, Karen. Parler à la troisième personne: the doubling of the narrative Céleste Albaret and Marcel Proust. Albaret, 1991.

3 Sobre servos em peças teatrais ver EMELINA, Jean. Les valets et les sevants dans le theater comique en France de 1610 à 1700. Grenoble : PUG, 1975.; GOUVERNET, Gérard. Le type du valet chez Moliere et ses successeurs. Regnard, Dufresny, Dancourt et Lesage. New York/Berne/Frankfurt: P. Lang, 1985. Sobre servos na literatura ver DI FAZIO, Alberti Margherita. II servo nella narrativa italiana della prima metà dell'ottocento. Napoli: Liguori, 1982; PAGLIANO, Graziella. Servo e padrone: I'orizzonte dei testi. Bologna: II Mulino, 1983; ROBBINS, Bruce. The servants hand : English fiction from below. London/Durham: Duke U.P., 1993; CASALINI, Maria. Pour une histoire de la domesticité au XIXe siècle. Quelques considérations à partir d' une étude sur Florence. (mimeo) ; e CASALINI, Maria. Senvitú, nobili e borghesi nella Firenze dell'Ottocento. Firenzi: Olschki, 1997, p.127-142. Para Futuras referências ver o catálogo da Library of Congress (http://catalog.loc.gov/), assunto "servants in literature".

4 Para autobiografias ver SANS, Gène Marie. J ugenderinnerungen eines armen Dienstmädchens. Bremen: Röver 1973; WEGREINER, Maria. Der Lebensroman einer Arbeiterfrau von ihr selbst geschrieben. Frankfurt/ New York, 1979.; BURNETT, John. (ed.) Useful toil: autobiographies of working people from the 1820s to the 1920s. London/ New York: Routledge, 1994; LAMOUILLE, Madeline. Pipes de terre et pipes de porcelaine: souveniers d'une femme de chambre em Suisse romande, 1920-1940. edit. by Luc Weibel. Genéve: Éditions Zoé, 1978; KIENZLE, Birgit. J ulie die Magad. "Ich habe nur ein recht gehabt, keines zu haben". Hamburg: Rowohlt, 1983; CULLWICK, Hannah. The diaries of Hannah Cullwick, victorian maidservant. (ed. By Liz Stanley) New Brunswick/NJ: Rutgers university Press, 1984. Sobre as autobiografias dos servos ver MITTERAUER, Michael. I servi nelle Alpi. Quaderni storici, vol.68, p.437-467, 1988; ARRU, Angiolina. Nel carattere scortese, nel comportamento impertinente e sfrontata. Racconti di serve tedesche nell'Ottocento. In: ARRU, Angiolina, CHIALANT, Maria Teresa. (eds.) II racconto delle donne. Voci autobiografie figurazioni. Napoli: Guida, 1990, p.11-26. Sobre os estudos históricos sobre serventes ver REGGIANI, Flores. Domestici e domesticità. "Marginalia" ad um tema emergente. Società e storia, vol.12, $n^{\circ} .43$, p.133-164, 1989; TILLY, Louise. Does waged domestic labor have a future? International Labor and Working-Class History, vol.39, p.61-71, 1991; SARTI, Raffaella. Il servizio domestico come problema storiografico. Storia e Problemi Contemporanei, n'.20, p.159-184, 1997.

5 SARTI, Raffaella. Per una storia del personale domestico in Itália. II caso di Bologna (sec. XVIII-XIX). Torino: Università degli Studi di Torino, 1994, capítulo 1. (Tese, doutorado); SARTI, Raffaella. The true servant. 
são, mas por puro e sincero prazer, tendo grande afeição pela virtude de seu mestre". Os que estão nessa posição "são chamados de servos mas, na verdade, são cortesãos". ${ }^{6}$

Há também uma forte impressão de ambigüidade quando lemos outros trabalhos, como Convito Morale pergli Etici, Economici, e Politici, de Pio Rossi. A partir dele podemos perceber que há varias possibilidades para o uso da palavra "servo". Nesse caso não apenas do ponto de vista social, como também do teológico e do filosófico: "o bom Príncipe, a quem é confiado o bem estar de seu povo, deve servir todos seus súditos"; o papa é servus servorum dei. Existem três tipos de servidão: a "por punição", da qual os teólogos falam, que é a servidão pelo pecado; a servidão "alcançada pela razão do povo", de que falam os juristas, que começou quando inimigos capturados foram escravizados; e o tipo "natural pelo nascimento", do qual filósofos, particularmente Aristóteles, comentam. ${ }^{7}$

Apesar do rigor do tom, textos legais, como II dottor volgare, de Giambattista De Luca, sob o tópico "servidão" unem elementos que para nós não têm nada em comum. Em primeiro lugar, De Luca faz uma distinção entre a servidão que afeta o status de uma pessoa, isto é que transforma um homem livre em escravo, e a desempenhada por um homem livre. Nesse segundo exemplo, ele distingue aqueles que devem serviços a outra pessoa "por causa de um contrato envolvendo seu trabalho" e aqueles que o devem por outras razões, como no caso de "obrigações unindo vassalos aos seus Barões, ou Lordes", ou no caso de "servidão de um filho para com seu pai". 8

A última afirmação pode ser particularmente surpreendente para nós, mas não devemos esquecer que a família foi uma instituição hierárquica durante séculos, como confirmado pela história do próprio conceito. Com certeza a palavra italiana "famiglia", a francesa "famille", a inglesa "familly", a alemã "familie", a portuguesa "família", todas derivaram diretamente ou indiretamente do latim "familia", que originalmente significava "corpo de servos" (servo= famulus). Mais tarde, a palavra familia assumiu outros significados também. Particularmente, foi usada para se referir a todo o grupo de pessoas sujeito à autoridade de um pai, como as esposas e crianças, assim como os servos (excluindo o próprio pai). ${ }^{9} \mathrm{O}$ fato de que

6 GOZZE, Nicolò Vito di. Governo della famiglia. Lucca: S. Paulino, 1589, p.100-116.

7 ROSSI, Pio. Convito morale.... Venetia: Gueriglij, 1639-1657, vol.1, p.380-381. Sobre os defensores da ideologia aristocrática que concordam com a existência de servos por natureza, ver ANGELOZZI, Giancarlo. La trattatistica su nobilità e onore a Bologna nei secoli XVI e XVII. Atti e memorie della Deputazione di storia patria per le Province di Romgna, n.25/26, p.187-264, 1974-75; BIONDI, Albano. II "Convito" di don Pio Rossi: società chiusa e corte ambigua. In: La corte e il "cortegiano". Roma: Bulzonni, 1980, p.93-112; FRIGO, Daniela. II padre di famiglia. Governo della casa e governo civile nella tradizione dell'economica' tra Cinque e Seicento. Roma: Bulzoni, 1985.

8 DE LUCA, Giambatista. II Dottor Volgare.... Colônia: a spese di Modesto Fenzo Stampatore in Venezia, 1755, vol.1, t.1, p.472. (1 ${ }^{\mathrm{a}}$. edição 1673)

9 SARTI, Raffaella. Europe at home: family and material culture, 1500-1800. London/New Haven: Yale University Press,2002. 
a familia e os termos dela derivados possam ser usados com esse significado confirmam que a família, por um longo período, foi uma comunidade de pessoas unidas por relações assimétricas que, por mais diferente que fossem (marido/mulher; pais/filhos; mestre/servo), todos dividiam algo com a relação mestre/servos. De fato, não apenas os servos, como as crianças e esposas também deveriam obedecer ao "paterfamilias". ${ }^{10}$ Obviamente havia esposas, crianças e servos que eram desobedientes ou que puderam negociar com o paterfamilias uma posição menos assimétrica, como no caso de Antonio Guberti, analizado por Angiolina Arru, ${ }^{11}$ mas normas e regras culturais estabeleciam papéis muito desiguais entre eles. ${ }^{12}$ Conseqüentemente, é surpreendente para nós, mas consistente com o quadro cultural das sociedades européias pré-industriais, que "membros fracos da família poderiam ser confundidos com servos", como afirmado por Giulia Calvi. ${ }^{13}$ Claramente, isso contribui com um crescimento da área de narrativas sobre servos. O grupo de pessoas que por uma razão ou outra foram incluídos na categoria daqueles submetidos à servidão por esse ou aquele autor parece aumentar até o infinito: de camponeses a cortesões, de filhos a papas, de escravos a vassalos.

Na Europa pré-industrial, de fato, o serviço doméstico não era um trabaIho específico, mas sim um tipo de relação que poderia existir entre pessoas de classes sociais, origem geográfica, treinamento, renda, afazeres, sexo, idade e status legal e civil diferentes. Um servo/serviçal foi definido como tal porque ele ou ela tinha um mestre, e não porque ele ou ela desempenhava uma tarefa específica. Ser serviçal era antes uma condição e não uma profissão. Isso não era uma condição absoluta: servos/serviçais podiam por sua vez ser mestres, assim como filhos podem ser pais. ${ }^{14}$

Então, por um lado, os elementos distintivos de ser um servo poderiam parecer claros, mas de outro lado, identificar servos do ponto de vista sociológico apresentava problemas consideráveis. No contexto dos estudos históricos, tudo isso trouxe à tona a coexistência de diferentes definições da

10 SARTI, Raffaella. Vita di casa. Abitare, mangiare e vestire nell'Europa moderna. Roma-Bari: Laterza, 2000, p.2732. O termo italiano "famiglia" foi usado com o significado de "servos" até 1930, mas no começo do século XIX esse significado era muito raro. A palavra francesa "famille" e a inglesa "familly" pareciam ser usadas com esse significado até o século XVIII. SARTI, Raffaella. Vita di casa, p.169-170. É mais difícil avaliar a duração do uso do termo para referir a todo o grupo de pessoas submissas ao pai.

11 ARRU, Angiolina. II credito dei servi, paper apresentado no seminário Narratives of the Servant (mimeo); ARRU, Angiolina. II servo. Storia di una carriera nel settecento. Bologna: II Mulino, 1995.

12 FRIGO, Daniela. II padre di famiglia; SARTI, Raffaella. Obbedienti e fedeli. Note sull'instruzione morale e religiosa di servi e serve tra Cinque e Settecento. Annali dell'Istituto Storico Italico-germanico in Trento, vol.17, p.91-120, 1991; ZARRI, Gabriella. (ed.) Donna, disciplina, creanza cristiana dal XV a XVII secolo. Studi e testi a stampa. Roma: Edizioni di Storia e Letteratura, 1996.

$13 \mathrm{CALVI}$, Giulia. Service, deference and affection: families and their servants in early modern Tuscany, paper apresentado no seminário Narratives of the Servant (mimeo).

14 FAIRCHILDS, Cissie. Domestic enemies. Servants and their masters in Old Regime France. Baltimore/London: The John Hopkins UP, 1984, p.2-3; SARTI, Raffaella. II servizio domestico: um canale di mobilità sociale? II caso di Bologna (fine '700-inizio '900) in Societá Italiana di Demografia Stotica. Disuguaglianze: straticazione e mobilità sociale nelle popolazioni italiane (dal secolo XIV agli inzi del secolo XX). Bologna: Clueb, 1997, vol.1, p.152. 
noção de serviço. Então, não é uma surpresa que a variedade de definições adotadas causou muita controvérsia entre os estudiosos. ${ }^{15}$ Mas não são apenas os estudiosos contemporâneos que discutem o quanto é apropriado as categorias empregadas. As pessoas dos séculos passados às vezes também discutiam a definição correta da palavra "servo/serviçal", apesar de que, no dia-a-dia, eles conseguiam entender o sentido do termo a partir do contexto no qual ele havia sido empregado. Às vezes, os próprios serviçais também podiam participar dessa discussão. Nesse sentido, no século XVIII, em Bolonha, Itália, a Confraria de San Vitale, que do final do século XVII até o final do século XIX reuniu os criados domésticos da cidade, definiu autoritariamente quais eram os "verdadeiros serviçais". Em 1753, particularmente, os membros decidiram admitir na irmandade apenas "serviçais verdadeiros dos seguintes tipos e não outros, isto é: ministros, 'cappenere', 'staffieri', lacaios, primeiros cocheiros, segundos cocheiros, principais montadores (cavalcanti), chefes de cozinha, sub-chefes de cozinha com trabalhos apenas de um serviço e mordomos". Eles também tinham que satisfazer a condição de não ter que desempenhar "em público" "qualquer tipo de trabalho desvalorizado" que pudesse fazer com que fossem considerados qualquer outra coisa diferente de "servos/serviçais verdadeiros". Com isso, "os comumente chamados meninos de cozinha, ou meninos que lavam a louça, meninos do estábulo, e carregadores" eram excluídos. Carregadores, em particular, eram excluídos, mesmo se trabalhassem para um único mestre como carregadores de cadeiras e fossem assalariados. A explicação era que, já que seu trabalho não era muito procurado, geralmente, quando terminavam a tarefa, aceitavam "trabalhos desprezíveis" "nas ruas". Essa definição de "verdadeiro serviçal" é muito surpreendente para nós, mas na sociedade do Antigo Regime ser servo não era necessariamente uma condição humilde. Acima de tudo, os membros da irmandade estavam buscando uma estratégia de prestígio: eles tentavam se definir como representantes de um trabalho que (pelo menos publicamente) não envolvia executar tarefas vis e degradantes. ${ }^{16}$

Apesar de que nessa Babel de narrativas e discursos sobre os servos nós também podemos ouvir a voz dos servos em si, muitas narrativas antigas sobre os servos tinham como objetivo regrá-los. A Hagiografia também foi usada com esse objetivo. Então, as páginas a seguir se concentram em um tipo particular de narrativa sobre servos, as Vidas de servos sagrados. Em particular, foca a Vida de uma santa medieval, Zita de Lucca. Discute como sua imagem foi modificada com o objetivo de transformá-la em um modelo a ser imitado, especialmente pelos servos, entre os séculos XVI

15 SARTI, Raffaella. II servizio domestico come problema storiografico; e SARTI, Raffaella. The true servant.

16 Riforma de Capitoli e Statuti della Congregazione di S. Vitale.... Fatta l'anno 1753. Bologna: Longhi Stampatore Arcivescovile, p.6 e 13-14; SARTI, Raffaella. L'Università dei servitori di Bologna; e SARTI, Rafaella. The true servant. 
e XVIII. Porém, antes disso, descreve a estratégia elaborada pela Igreja Católica, nos séculos XVI e XVII, para impedir a disseminação da Reforma Protestante, dando atenção particular ao papel dado à hagiografia. Então, passa a mostrar como a história de Zita pode se ajustar à política de restauração moral e religiosa buscada pela Igreja Católica no século XIX e também em momentos do século XX. Em seguida, analisa como a mesma história foi contada diferentemente em diversos contextos culturais e sociais e por autores com objetivos diferentes. As várias versões da história, como já está explicitamente sugerido, não são contadas apenas devido às diferentes personalidades e objetivos dos autores, como também por causa dos diversos contextos culturais e socioeconômicos em que a mesma foi recontada. Nesse sentido, após analisar a "história das histórias de Zita", chama-se a atenção para as transformações socioeconômicas por que passaram os serviços domésticos, particularmente no que diz respeito ao aumento das taxas de feminilidade entre os mesmos, tentando entender as implicações e conseqüências mais gerais desse aumento à luz da História Social e de Gênero.

\section{A estratégia da Igreja Tridentina}

Entre os séculos XVI e XVII, tentativas de impedir a expansão da Reforma Protestante e de reformar a Igreja Católica resultaram no desenvolvimento de um projeto para criar uma sociedade alerta e hierárquica. O projeto foi baseado na interpretação Tridentina do Quarto Mandamento, "honre teu pai e tua mãe". De acordo com essa interpretação, superiores e inferiores estavam unidos por uma forte, porém assimétrica, corrente de obrigações mútuas. É verdade que, a obrigação de honrar seus pais era estendida a todas as mães metafóricas e a - quase todos - os pais, o que quer dizer mestres, pessoas do clero, governadores, tutores, professores, velhos... Era explicado que o respeito devido a eles vinha de Deus, já que Ele governava a sociedade através daqueles que Ele apontou como autoridades. Conseqüentemente, respeito deveria ser traduzido em obediência. Com isso, a interpretação Tridentina do Quarto Mandamento garantia o respeito a todos superiores e estendia o respeito filial para além das fronteiras da família. Além disso, essa interpretação fixava as tarefas e responsabilidades dos superiores em relação a seus subordinados: dar a seus filhos, biológicos ou não, as regras boas e sagradas da vida, e exigir seu respeito. ${ }^{17}$

17 Catechismus, Ex Decreto Concilii Tridentini, Ad Parochos, Pii V Pont. Max. Iussu Editu, Romae, In aedibus Populi Romani, apud Paulum Manutium, 1566, p.250-258; BIONDI, Albano. Aspetti della cultura cattolica post-tridentina. Religione e controllo sociale. In: VIVANTI, Corrado. Storia d'Italia. Annali 4, Intellettuali e potere, a cura di C. Vivanti. Torino: Einaudi, 1981, p.260-268; PROSPERI, Adriano. Intellettuali e Chiesa all'inizio dell'tà moderna. In: VIVANTI, Corrado. Storia d'Italia, p.214; BOSSY, John. L'occidente cristiano, 1400-1700. Torino: Einaudi 1990, p.137 (ou. Christianity in the West, 1400-1700. Oxford: Oxford University Press, 1985, p.137). 
Um grande esforço foi feito para moldar a sociedade de acordo com esses princípios e valores. ${ }^{18} \mathrm{~A}$ palavra foi instrumento muito importante nesse sentido, especialmente a escrita. A "batalha dos livros" foi deflagrada colocando no mercado livros de prece, contos de milagres, catecismos, regras, instruções, lições e guias. ${ }^{19}$ Passado algum tempo, cada fiel conseguiu encontrar pelo menos um texto que apontasse o comportamento ideal de acordo com seu status. ${ }^{20}$ Isso era provavelmente inevitável, já que era genericamente afirmado que qualquer um, cumprindo com sua própria tarefa, poderia "agradar a Deus". ${ }^{21}$ Servos também.

Parece que, no começo, era dever de pregadores, padres e mestres ensinar aos serviçais suas tarefas. Mas do final do século XVII ao começo do século XVIII, os próprios servos podiam achar livros destinados diretamente a eles, que explicavam as regras que deveriam seguir para serem perfeitos Cristãos. Dessa forma, os servos podiam aprender como se comportar não apenas ouvindo os pregadores, padres e mestres, mas também lendo esses livros. ${ }^{22}$

\section{0 bom servo}

Mas como deveria se comportar o bom servo? Obediência sempre foi a maior característica de um bom serviçal. ${ }^{23}$ Uma característica típica da era pós-Tridentina, contudo, é a ênfase na obediência ao seu mestre, como tenentes de Deus. "Servos, obedeçam a seus mestres terrenos com medo e temor (...) como servindo a Cristo": essa frase de São Paulo (Carta para o Ephesians 6, 5-7), do final do século XVI, tornou-se provavelmente mais popular do que jamais tinha sido. ${ }^{24}$ Contudo, a insistência na identidade

18 BIONDI, Albano. Aspetti della cultura cattolica post-tridentina; PROSPERI, Adriano. Intellettuali e Chiesa all'inizio dell'tà moderna; PRODI, Paolo, PENUTI, Carla. (eds.) Disciplina dell'anima, disciplina del corpo e disciplina della società tra Medioevo ed età moderna. Bologna: II Mulino, 1994. Nessa estratégia e no debate sobre a categoria de "Sozialdisziplienierung" ("disciplinamento social"), ver PROSPERI, Adriano. Riforma cattolica, crisi religiosa, disciplinamento: um percorso di ricerca. Annali dell'Instituto storico ítalo-germanico in Trento, v.19, p.401-415, 1993; ALESSI, Giorgia. Discipline. I nuovi orizzonti del disciplinamento sociale. Storica, v.2, n.4, p.7-37, 1996; CAFFIERO, Marina. Religione e modernità in Itália (secoli XVII-XIX). Pisa/Roma: Instituti Editoriali e Poligrafici, 2000; entre outros.

19 Catechismus, ExDecreto Concilii Tridentini, p.2-3; GINZBURG, Carlo. Folklore, magia, religione. In: VIVANTI, Corrado. Storia d'Italia, vol. I, I caratteri originali. Torino: Einaudi, 1972, p.650-659; BIONDI, Albano. Aspetti della cultura cattolica post-tridentina, p.299; BOSSY, John. Christianity in the West, 1400-1700, p.115-123. Deve ser destacado que a Igreja Católica proibiu a livre leitura da Bíblia, ver FRAGNITO, Gigliola. La Bibbia al rogo: la censura eclesiástica e i volgarizzamenti della Scrittura, 1471-1605. Bologna: II Mulino, 1997.

20 CASALI, Elide. "Economica" e "creanza" cristiana. Quaderni storici, vol.14, p.555-583, 1979; e CASALI, Elide. II villano dirozzato. Cultura società e potere nelle campagne romagnole della Controriforma. Firenze: La Nuova Italia, 1982, particularmente p.35-52; FRIGO, Daniela. II padre di famiglia; SARTI, Raffaella. Obbedienti e fedeli; ZARRI, Gabriella. (ed.) Donna, disciplina, creanza cristiana dal XV a XVII secolo.

21 ANTONIANO, Silvio. Tre libri dell'Educatione Christiana dei Figliuoli. Verona: dalle Donne e Stringari,1584, p.166v

22 SARTI, Raffaella. Obbedienti e fedeli.

23 Por exemplo PIETRI, Charles. Lês chrétiens et lês esclaves aux premiers temps de l'Église (II-III siècles). Concilium, n.150, p.47-55, 1979

24 Por exemplo CORDIER, Jean. La Famille Sainct. Paris: Bechet, 1666, vol.I, p.413; FLEURY, Claude. Devoirs des maîtres et des domestiques. Paris/Auboiun: Clouzier, 1688, p.79; FONTANA, Aldigherio. La senvitù instruita. Milano/Bologna: F. Pisarri, 1710, p.19; Istruzioni Sspra gli Obblighi sì generali che particolari d'ogni Cristiano che viva 
entre um mestre na terra e um Mestre no céu criava sérios problemas. É certo que os servos tinham que obedecer a um mestre ainda que "mal educado", "malvado", "abusado", "excêntrico", "desagradável e insuportável", "irracional, teimoso e impiedoso". ${ }^{25}$ Mas o que eles deviam fazer quando as ordens do mestre colidiam com a lei divina? "Ah! Tenham cuidado em não obedecê-los nesse caso" - um pregador grita para os servos domésticos. ${ }^{26}$ Nessas circunstâncias, os mestres estão abusando de seu poder. Não há duvidas: em se tratando desse assunto, a diferença entre os autores era apenas uma questão de relevância e espaço concedidos a esse difícil tópico. ${ }^{27}$

Obediência ao seu mestre é considerada uma característica distintiva de um servo que se comporta como um Cristão perfeito. Mas muitos autores viam a lealdade como a principal virtude dos servos. ${ }^{28}$ Para o servo, lealdade significa ser discreto sobre a vida da família; significa supervisionar o comportamento de outros servos; cuidando das necessidades do mestre com cuidado. Acima de tudo, significa respeito a suas propriedades. ${ }^{29} \mathrm{~A}$ interpretação Tridentina do Sétimo Mandamento ("Você não deve roubar") condena os servos que roubassem bens de seus mestres. 30 "O Estábulo ou Porão do mestre não te pertence, nem sua bolsa", avisa o jesuíta Cordier. Ele considera o "roubo doméstico" da mesma maneira que o "mais cruel assalto". Esse é o "perpetrado na Casa de Deus". Com isso, condena os servos que dão bens de seu senhor sem permissão! Dar esmolas (como alguém disse) não é uma exceção à regra. ${ }^{31}$

nel secolo. Venezia: Rossi, 1796, p.227-228 (a parte sobre servos foi copiada de FLEURY, Claude. Devoirsdes maîtres et des domestiques); BRESSANVIDO, Idelfonso da. Instruzioni Morali. Genova : Olzati, 1778, vol.2, p.180 e 182, etc.

25 CORDIER, Jean. La Famille Sainct, vol.I, p.413; FONTANA, Aldigherio. La servitù instruita, p.19; FLEURY, Claude. Devoirs des maîtres et des domestiques, p.81; Istruzioni Sspra gli Obblighi sì generali che particolari d'ogni Cristiano che viva nel secolo, p.228; BÉNIGNE, Lordelot. Les devoirs de la vie domestique. Paris : Émery, 1706, p.74; BRESSANVIDO, Idelfonso da. Instruzioni Morali, vol.2, p.182.

26 BRESSANVIDO, Idelfonso da. Instruzioni Morali, vol.2, p.182.

27 CORDIER, Jean. La Famille Sainct, vol.I, p.413; BÉNIGNE, Lordelot. Les devoirs de la vie domestique, p.74; FONTANA, Aldigherio. La senitù instruita, p.19, 22; FONTANA, Aldigherio. La donzela he serve instruita. Milano/Bologna: F. Pisarri,1710, p.19-20; Istruzioni Sspra gli Obblighi sì generali che particolari d'ogni Cristiano che viva nel secolo, p.129; Celnart, 1836, p.9.

28 CORDIER, Jean. La Famille Sainct, vol.I, p.406; FLEURY, Claude. Devoirs des maîtres et des domestiques, p.82; Istruzioni Sspra gli Obblighi si generali che particolari d'ogni C ristiano che viva nel secolo, p.231; BRESSANVIDO, Idelfonso da. Instruzioni Morali, p.184

29 CORDIER, Jean. La Famille Sainct, vol.I, p.406-411; FLEURY, Claude. Devoirs des maîtres et des domestiques p.82-85; BÉNIGNE, Lordelot. Les devoirs de la vie domestique, p.73-74; FONTANA, Aldigherio. La donzela che serve instruita, p.20-22; FONTANA, Aldigherio. La servitù instruita, p.20-21; Istruzioni Sspra gli Obblighi sì generali che particolari d'ogni Cristiano che viva nel secolo, p.231-233; BRESSANVIDO, Idelfonso da. Instruzioni Morali, p.184-186.

30 Catechismus, Ex Decreto Concilii Tridentini, p.272. Sobre roubos domésticos MANZINI, Vicenzo. Trattado Del furto e delle varie sue specie. Le varie specie di furto nella storia e nella Sociologia. Torino: Utet, 1902-12, parte 1, vol.2, p.718-721; LION, Arturo. Famulato. In: Enciclopédia Giuridica Italiana. Milano: Società Editrice Libraria, 1900, p.694-704; CASALINI, Maria. Senvitú, nobili e borghesi nella Firenze dell'Ottocento, p.143-162 e CASALINI, Maria. Pour une histoire de la domesticité au XIXe siècle.

31 CORDIER, Jean. La Famille Sainct, p.409; FLEURY, Claude. Devoirs des maîtres et des domestiques, p.106 FONTANA, Aldigherio. La servitù instruita, p.21-22,30; FONTANA, Aldigherio. La donzela che serve instruita, p.31; Istruzioni Sspra gli Obblighi sì generali che particolari d'ogni Cristiano che viva nel secolo, p.232-233. 


\section{Modelos para servos}

"Entre todos os livros de caridade, não existe um que seja mais educativo e útil do que a Vida dos Santos", escreveu um autor. Esses livros fornecem "para qualquer idade, sexo e condição, modelos que são apropriados para as atividades de todos": suas histórias são uma "moral simplificada em trabalhos e exemplos". ${ }^{32}$

A partir da era pós-Tridentina, os santos foram, com mais freqüência do que no passado, descritos como exemplos e campeões de virtudes. ${ }^{33}$ O programa educacional da Igreja Católica tinha como objetivo não apenas transmitir normas abstratas de comportamento, mas também disponibilizar a todos modelos práticos a serem seguidos. Era dito que "heróis Cristãos" poderiam ser achados em qualquer status social. Havia também provas disso, como foi demonstrado por muitos autores. Por exemplo, em seu livro, La Santità, e la Pietà trionfante In ogni Dignità, Conditione e Stato, Giovanni Fontana explicava a qualquer um quais as regras que deveriam ser seguidas para que se tornasse um cristão perfeito. Além disso, ele incluiu a vida de alguns santos que poderiam e deveriam ser tomados como exemplos pelo indivíduo comum. Claro, o autor não deixou de mencionar servos. ${ }^{34}$

A partir de meados do século XVII, padres, pregadores e mestres paroquiais passaram a chamar a atenção dos serviçais para santos que passaram suas vidas como serviçais, tais quais Bonifácio, Agatodoro, Vitale, Euno, Agatoclia, Dula, Matrona, Blandina, Potamiana, Verdiana, Armella Nicolas, entre outros. A partir do final do século XVII, as histórias de vida desses santos tomaram a forma de livros portáteis, direcionados diretamente aos servos. ${ }^{35}$ Santa Zita, que viveu em Lucca no século XIII, também foi uma serva. ${ }^{36}$

32 CROISET, Jean. Les vies des saints. Lyon: Vve. De A Boudet, 1723, vol.1, Prefácio (páginas não numeradas).

33 SALLMAN, Jean-Michel. II santo e le rappresentazioni della santità. Problemi di metodo. Quaderni storici, vol.14, p.584-602, 1979, p.593; VAUCHEZ, André. Santità. In: Enciclopédia, vol.12, 1981, p.452 ; BOSSY, John. L'occidente cristiano, 1400-1700, p.114 ; ZARRI, Gabriela. Le sante vive. Profezie di corte e devozione femminile tra '400 e '500. Torino: Rosenberg \& Sellier, 1990, p.87; ZARRI, Gabriela. (ed.) Finzione e santità tra medioevo ed età moderna. Torino: Rosenberg \& Sellier, 1991 ; PROSPERI, Adriano. L'elemento storico nelle polemiche sulla santità. In: ZARRI, Gabriela. (ed.) Finzione e santità tra medioevo ed età moderna, p.112. Para mais detalhes SARTI, Raffaella. Zita, serva e santa, p.309 e 331, notas de rodapé 30 e 31. Sobre as funções de santos ver DELOOZ, Pierre. Sociologie et canonizations. Liège: Facultè de Droit/ Le Haye: Martinus Nijhoff, 1969; VAUCHEZ, André. La sainteté em Occident aux derniers siècles du Moyen Age. Rome: École Françoise de Rome, 1981; BOESCH GAJANO, Sofia, SEBASTIANI, Lucia. (eds.) Culto dei santi, istituzioni e classi sociali in età preindustriale. L'Aquila/Rome: Japadre, 1984; BARONE, Giulia, CAFFIERO, Marina, SCORZA BARCELLONA, Francisco. (eds.) Modelli di santità e modelli di comportamento. Contrasti, intersezioni, complementarità. Torino: Rosenberg \& Sellier, 1994; BOESCH GAJANO, Sofia. (ed.) Santità, culti, agiografia. Temi e prospettive. Roma: Viella, 1997; BOESCH GAJANO, Sofia. La santità. Roma/Bari: Laterza, 1999.

34 CROISET, Jean. Réflexions chrétiennes sur divers sujets de morale. Paris : Edme. Couterot, 1707, p.242; FONTANA, Aldigherio. La santità, e la pietà triunfante. Venecia: Poletti, 1716, parte 1, p.473-474; parte 2, p.84-87.

35 SARTI, Raffaella. La donzella Che serve instruita': norme e modelli di comportamento per il personale domestico femminile tra XVII e XVIII secolo. In: DATINI, F. La donna nell'economia, sec. XIII-XVIII. Prato: Istituto Internazionale di Storia Economica, 1990; SARTI, Raffaella. Obbedienti e fedeli; SARTI, Raffaella. Zita, serva e santa; LOMBARDI, Daniela, REGGIANI, Flores. Da assistita a serva. Circuito di reclutamento delle serve attraverso lê istituzioni assistenziali (Firenzi-Milano, XVII-XVIII séc.). In: DATINI, F. La donna nell'economia, sec. XIII-XVIII, p.309-310.

36 Zita nasceu em Monsagrati, no interior de Lucca, e entrou no serviço domestico com doze anos, assim como outras servas sagradas. Ver BENVENUTI PAPI, Anna. Santità femminile nel território Fiorentino e lucchese; considerazioni 


\section{Zita}

Em 1697, um autor anônimo publicou a Vida de Zita com o propósito de "fornecer a todos aqueles que têm um trabalho humilde um efetivo estímulo para a virtude, seguindo o exemplo dessa abençoada serva (...) e assim aprenderem como lealmente servirem seus mestres na terra e serem, ao mesmo tempo, verdadeiras crianças para seu Pai no céu". ${ }^{37}$ Na realidade, a primeira Vida de Zita, escrita algum tempo depois de sua morte, conta que ela tinha sido, por mais de quarenta anos, uma serva da família nobre Fatinelli, que nunca dera espaço para ociosidade e que trabalhara "sem censura ou culpa". ${ }^{38}$ Então, ela era uma serva ideal? Bem, não exatamente.

De acordo com seu primeiro biógrafo, cujo livro em latim fora provavelmente escrito por volta do começo do século XIV, Zita fazia longas peregrinações, retornando para a casa muito tarde da noite. Ela ficava tão absorta nas preces que se esquecia de assar o pão, Na noite de Natal ela emprestou o manto que havia pegado emprestado de seu mestre - que a avisou para tomar muito cuidado com ele - para um homem pobre que estava com frio, mas que de repente desapareceu. Durante uma crise de fome, sem permissão, alimentou os famintos com todo o feijão pertencente a seu senhor que estava em um grande baú. ${ }^{39}$ Para resumir, ela não era obediente, nem correta, nem respeitava a propriedade de seu mestre.

Esse primeiro livro sobre a Vida dessa serva do começo do século $\mathrm{XIV},{ }^{40}$ reflete a atmosfera religiosa, assim como os modelos de santidade desse período. Zita brilhou com caridade e devoção, rigor acético e virgindade, humildade e docilidade. Essa hierarquia de valores difere daquela insistentemente transmitida aos servos pelos textos educacionais da era pós-Tridentina. Obediência e lealdade ao mestre são virtudes secundárias. ${ }^{41}$ Mais ainda, essas virtudes estão muitas vezes em conflito com a lealdade e obediência ao Senhor que está no céu. Mas os milagres colocaram um

intorno al caso di Verdiana da Castelfiorentino. Religiosità e società in Valdesa nel Basso Medioevo, Biblioteca della Miscellanea Storica della Valdesa, n.3, p.112-116, 1980. Ela trabalhou como serva até sua morte, mais ou menos com a idade de sessenta. O ano de sua morte é controverso mas provavelmente 1278 é o correto. Para mais detalhes sobre sua vida ver SARTI, Raffaella. Zita, serva e santa, p.332, nota de rodapé 35, p.325-326.

37 Al Divoto Lettore. In: Vita di Santa Zita... Roma: Komarek, 1697, páginas não numeradas.

38 Vita ab auctore coevo descripta. Ex códice Ms. Camaldolensi, collato cum Originali Lucensi. In: Acta Sanctorum Aprilis. Antverpiae: apud Michaelem Cnobarum, 1675, vol.3, p.499.

39 Vita ab auctore coevo descripta, p.502,503,501,500.

40 SARTI, Raffaella. Zita, serva e santa, p.333, nota de rodapé 40.

41 Entre outros trabalhos ver VAUCHEZ, André. La sainteté em Occident aux derniers siècles du Moyen Age, p.359363; VAUCHEZ, André. Les laïcs au Moyen Age. Praticques et experiences religioses. Paris: Les Editions du Cert, 1987, p.214-218; BELL, Rudolf, WEINSTEIN, Donald. Saints and society: the two worlds of western Christendom, 1000-1700. Chicago: University of Chicago Press, 1982; WILSON, Stephen. Saints and their cults: studies in religious sociology, folklore and history. Cambridge: Cambridge University Press, 1983; WALKER BYNUM, Caroline. Holy feast and holy fast. The religious significance of food to medieval women. Berkeley/Los Angeles/London: University of California Press, 1987; BARONE, Giulia. Società e religiosità femminile (750-1450). In: SCARAFFIA, Lucetta, ZARRI, Gabriela. (eds.) Donne e fede. Santità e vita religiosa in Itália. Roma/Bari: Laterza, 1994, p.61-113. o primeiro hagiógrafo nunca fala sobre lealdade mas fala duas vezes sobre a obediência de Zita. Mas ele apenas se refere à obediência ao mestre uma vez. Apesar disso, obediência é apresentada mais como um exercício ascético do que como uma tarefa do servo. Vita ab auctore coevo descripta, p.505,506. 
fim a esse conflito. Quando Zita negligenciava suas tarefas domésticas para servir a Deus, Deus, Ele mesmo, sempre a tirava dos problemas. Quando ela estava absorta em preces e se esquecia de assar o pão, Mãos divinas o faziam para ela. O dia em que ela emprestou a manta de seu mestre ao pobre homem, um ser supernatural a devolveu. Apesar dela ter esvaziado o baú de feijões para alimentar os famintos, o baú estava cheio quando o mestre o abriu. ${ }^{42}$ Nesse sentido, os interesses do mestre foram protegidos. Mas Deus não ajudou o mestre. Deus não veio para ajudar aqueles que seriam vistos como seus tenentes durante a era pós-Tridentina. Deus veio para salvar Zita, a serva que desobedecia a seu mestre em nome de sua lealdade a seu Mestre no céu.

O Senhor, Ele mesmo, explicou para Zita que "é melhor obedecer ao Senhor no céu do que ao mestre na terra". É por isso que Zita, durante a fome, distribuiu os bens de seu mestre, sem hesitar, para os famintos. $\mathrm{Na}$ verdade, ela havia sido instruída por Deus que, nos períodos de necessidade, tudo deveria ser dividido. Todos aqueles que clamavam os presentes do céu como sua propriedade privada são culpados diante de Deus; aqueles que não dividem sua propriedade com os famintos se tornam responsáveis por sua própria morte. Ao contrário, Zita, "Ancilla Dei", via os pobres como a imagem de Deus e, conseqüentemente, ela se considerava em primeiro lugar e de forma mais importante como uma serva dos pobres. ${ }^{43}$ Ela deveria dar a eles todos seus bens, seu dinheiro, comida, roupas, sapatos, enfim tudo que possuía. Mais ainda, ela não via essa tarefa como se oferecesse um presente, mas simplesmente como devolver aos pobres o que já era de fato deles. É verdade que, como o hagiógrafo anônimo observa, "quando damos aos pobres o que eles precisam estamos sendo justos, mais do que misericordiosos". ${ }^{44}$ Essa afirmação reflete a atmosfera religiosa em que a primeira Vida de Zita foi escrita, isso é, uma atmosfera em que pobreza dominava e emergiam discussões sobre a propriedade privada. ${ }^{45}$ Essa afirmação deve ser muito desconcertante para os leitores dos séculos que se seguiram. Os Bollandists sentiram a necessidade de retificá-la, e a referência chegou a ser literalmente retirada de Gregorius, o Grande. ${ }^{46}$

42 Vita ab auctore coevo descripta, p.503,501,500

43 Vita ab auctore coevo descripta, p.500. sobre a discussão medieval sobre esses temas ver COUVREUR, Gilles. Les pauvres ont-ils des droits? Recherches sur lê vol em cas d'extrême necessite depuis la Concórdia de Gratien (1140) jusqu'à Guillaume d'Auxerre (†1231). Roma : Libreria editrice dell'Università Gregoriana, 1961. Para mais detalhes ver SARTI, Raffaella. Zita, serva e santa, p.334-335, nota de rodapé 45

44 Vita Beatae Zitae.... Ferrariae: Ex Typographìa Filoniana, 1688, p.5; Biblioteca Statale di Lucca, ms.3540, c.149v150r ("cúm quaelibèt necessaria indifentibus ministramus, sua ilis reddimus, non nostra largimur; et justitiae potiùs debitum solvimus, quàm misericordiae opera impleamus").

45 Por exemplo VAUCHEZ, André. L'Ordine Francescano nei secoli XIII e XIV: tra ideale e realtà. In: Ordini mendicanti e società italiana XIII-XV secolo. Milano: Saggiatore,1976, p.233-243; VAUCHEZ, André. II posto della povertà nei documenti agiografici dell'epoca degli spirituali. In: Ordini mendicanti e società italiana XIII-XV secolo.

46 Gregorius o Grande, Regulae Pastoralis Liber, parte 3, capítulo 21, em PL, vol.77, col.87. Na Vida de Zita publicado no Acta Sanctorum dos Bollandists a frase "sua illis reddimus" foi mudada para "sua velut reddimus". Ver Vita ab auctore coevo descripta, p.500 (itálico meu). Apesar disso os editores adicionaram esta nota: "Hoc debitum non esse justitiae stricte dictae sanior Theologorum pars consentit et si qui ab iis verbo dissentiunt, reipsa convenire 
Caridade para os pobres e respeito à propriedade do mestre, lealdade ao Senhor no céu e lealdade ao senhor na terra, obediência devida a Deus e obediência devida ao mestre; a Vida de Zita claramente põe em discussão a relação entre essas questões. Contudo, vale a pena prestar atenção aos episódios de sua vida (principalmente ao do baú de feijões), analisando a maneira como os hagiógrafos de Zita lidaram com eles. Com isso, irei analisar suas escolhas, lembrando o contexto em que eles viviam, os seus propósitos finais e o público a que eles se dirigiam.

\section{Federighi e o Anônimo de 1697: o caso de extrema necessidade}

Em 1582, Giovanni Federighi publicou uma tradução medieval italiana da Vida de Zita, escrita em Latim. Durante os três séculos após a morte da santa, as pessoas mantiveram sua memória viva. Sua história havia se espalhado por meio da tradição oral e de cópias manuscritas da primeira Vida. ${ }^{47}$

Federighi foi convencido a escrever a sua história por Alessandro Fatinelli, herdeiro do mestre de Zita, cujo prestígio aumentaria com o culto da santa. Federighi não traduziu o texto de forma literal. Entretanto, ele achou que, na sua versão, nada de relevante havia sido adicionado ou emitido se comparado ao original: ele havia apenas enriquecido o original, adicionando algumas frases. De um ponto de vista geral, Federighi pode estar certo. Mesmo assim, sua versão apresenta algumas diferenças quando comparada com a original. Sobre a multiplicação dos feijões, o hagiógrafo medieval explica que, com esse milagre, Deus queria proteger Zita, poupando-a de ser censurada e de suas preocupações. Sobre esse tema, Federighi adiciona: "isso não significa que é certo doar os bens de seu mestre, exceto em casos de extrema necessidade". ${ }^{48}$ A intervenção de Federighi é limitada, mas altera o equilíbrio e o conteúdo do texto. Com certeza sua adição ao texto medieval tem como objetivo fazer com que a mensagem passada pela Vida de Zita fosse apropriada ao contexto cultural de sua época. Essa adição explica como a situação em que Zita distribuía feijão para os famintos era

cum eis debent, ne in absurdissimas consequentias trahantur: nisi cum casu extremae necessitatis agitur". Acta Sanc torum Aprilis, vol.3, p.501. Na realidade muitos teólogos, principalmente durante a Idade Média, mantinham a opinião criticada pelos Bollandists, ver GUZZETTI, Giovanni Battista. Elemosina. In: Enciclopedia Cattolica. Città Del Vaticano: Sansoni, v.5, 1950, cols.198-200; SPICQ, Ceslas. L'aumôme: obligation de justice ou de charité? In : Mélanges Mandonnet. Paris: Vrin, vol.1, 1930, p.245-264; LOTTIN, Odon. La nature du devoir de l'aumône chez les prédécesseurs de Saint Thomas d'Aquin. Ephemerides Theologicae Lovanienses, v.15, p.613-624, 1938; LIO, Ermegildo. II testo di S. Agostinho 'Justitia [est] in subveniendo miseris' in Pier Lombardo e nei suoi glossatori fino a S. Tommaso d'Aquino. In: Miscellanea lombardiana. Novara: De Agostini, 1957, p.175-222; COUVREUR, Gilles. Les pauvres ont-ils des droits?

47 FEDERIGHI, Giovanni. Vita e miracoli della vergine beata Zita. Lucca: Busdraghi, 1582; SARTI, Raffaella. Zita, serva e santa, p.336, notas de rodapé 58 e 59.

48 FEDERIGHI, Giovanni. Vita e miracoli della vergine beata Zita, dedicatória do livro para Alessandra e Ângelo Buonvisi, páginas não numeradas (papel de Alessandro Fatinelli), "A' Lettori", páginas não numeradas (frases adicionadas), p.14 (citação). 
peculiar: era um caso de "extrema necessidade", onde, segundo a Igreja, um servo podia dispor da propriedade de seu mestre..$^{49} \mathrm{O}$ autor tenta excluir qualquer dúvida sobre a lealdade de Zita, para evitar o risco de alguém, ao imitá-la, se comportar de maneira errada.

A disposição de Federighi é imitada pelo autor anônimo que, em 1697, publicou a Vida de Zita para disponibilizar aos servos um modelo a ser imitado. Contudo, ele insiste, mais do Federighi, em diferenciar aqueles casos em que os servos devem ter respeito pelos bens de seus mestres e as situações excepcionais em que podem usar desses bens sem permissão. ${ }^{50}$ De fato, Federighi estava escrevendo para um público geral; com objetivos educacionais amplos. Além disso, seu objetivo evidente era louvar os Fatinellis. Do outro lado, o autor desconhecido estava se direcionando às "pessoas incivilizadas" e, particularmente, aos servos domésticos, para ensiná-los a melhor maneira de servir seus mestres na terra e seu Mestre no céu: com isso, era necessário ser insistente. ${ }^{51}$ Mas sua insistência obstinada não pode ser explicada apenas com propósitos educacionais. É verdade que alguns anos antes (1679), o Papa Inocente XI havia condenado a afirmação que dizia que "é permitido roubar não apenas em casos de necessidade extrema, mas também em casos de necessidade séria". ${ }^{52}$ Se Zita não era uma ladra, ela tinha que ter se visto em uma situação de necessidade extrema. Após a intervenção do Papa, era necessário enfatizar que era esse o caso. ${ }^{53}$

\section{Franciotti e Fioriti: o exemplo de Zita de ser estimado e não seguido}

Para fazer com que o comportamento da santa fosse aceitável, alguns hagiógrafos mostraram que Zita se achou em circunstancias peculiares. Outros autores sublinharam que ela possuía uma relação excepcional com Deus. Cesare Franciotti (1613) conta a história de Zita e toma-a como um ponto de partida para algumas considerações mais amplas. Após estimular a caridade, ele tenta resolver a dúvida que "por acaso" pode surgir no "leitor devoto": "Podemos louvar Zita por ter distribuído a propriedade de seu mestre ao invés da sua?". Franciotti deixa bem claro: a não ser que haja

49 SIMEONE, Lorenzo. Furto. In: Enciclopedia Cattolica, 1950, v.5, cols.1818-1824; MANTOVANI, Ferrando. Furto (Diritto penale comune). In: Novíssimo Digesto Italiano. Torino: Utet, 1961, v.7, p.693-717. Ver SARTI, Raffaella. Zita, serva e santa, p.334, nota de rodapé 45 e p.338, nota de rodapé 70.

50 Vita di Santa Zita, p.57-59.

51 FEDERIGHI, Giovanni. Vita e miracoli della vergine beata Zita, "A' Lettori" (páginas não numeradas); Vita di Santa Zita, "Al Divoto Lettore" (páginas não numeradas).

52 DENZINGER, Heinrich. Enchiridion symbolorum definitionum et declarationum de rebus fidei et morum. Barcelona: Herder, 1948, n.1186, p.371 (4 de Março 1679). Teólogos distinguem três graus diferentes de necessidade (às vezes quatro), mas sem sempre concordarem sobre o grau de necessidade que torna o roubo lícito. Ver MANZINI, Vicenzo. Trattado Del furto e delle varie sue specie, parte 1, vol.1, p.427; CHRĖTIEN, P. Vol. In: Dictionnaire de Théologie catholique. Paris: Librarie Letouzey et Ané, 1950, v.15, part.12, cols.3282-3300; SIMEONE, Lorenzo. Furto; COUVREUR, Gilles. Les pauvres ont-ils des droits?

53 Ver SARTI, Raffaella. Zita, serva e santa, p.338, nota de rodapé 71. 
uma situação de necessidade extrema, a serva que distribui os bens de seu mestre aos necessitados está cometendo um verdadeiro "roubo". Contudo, Zita não merece ser culpada. Não porque ela agiu em uma situação de extrema necessidade, mas porque "ela foi forçada internamente por Deus; e também porque, pelo mesmo impulso interno, ela tinha certeza que as mercadorias iriam aumentar em vez de diminuir". Então, Franciotti diz que o exemplo de Zita "não deve ser seguido por aqueles que não alcançaram a perfeição dela e não tiveram suas revelações, já que eles não agradariam a Deus mas transgrediriam Sua lei e seriam condenados". ${ }^{54}$

Mais de um século depois, a mesma solução foi escolhida pelo padre Bartolomeo Fioriti. Em 1752, ele publicou a Vida da santa em um "pequeno livro de mão em uma linguagem fácil de compreender". Ele tinha certeza que o público o apreciaria. Ele explicou que era difícil achar livros que contassem a história da serva de Lucca. Além disso, a história dela havia sido incluída em algumas coleções de Vidas dos santos, que não eram fáceis de serem utilizadas já que eram constituídas de muitos volumes ou de um volume muito grande. Além disso, os textos em Latim eram escritos em uma linguagem que "não era conhecida por todos e era incompreensível para servas". Então, o objetivo de Fioriti era também falar com as servas domésticas. Sua principal preocupação era prevenir que os servos domésticos aprendessem o que não deviam. Uma preocupação tão profunda levou-o a dizer que "o exemplo de Zita deve ser apreciado mas não seguido, já que o episódio [da distribuição dos feijões] ocorreu em circunstâncias muito especiais, que dificilmente ocorreriam novamente". De acordo com Fioriti, a própria Zita obteve a santidade seguindo o modo "comum e seguro", que é executando as tarefas de seu nível. Apenas quando ela alcançou a perfeição como serva que ela teve permissão de "dar esmolas utilizando os bens de seu mestre sem sua permissão, e ser louvada ao invés de castigada por isso". ${ }^{5}$ Zita era um modelo de boa serva, mas ela não devia ser tomada como modelo quando ela se comporta como uma santa, já que - nesse caso - permissão especial foi dada por Deus.

Franciotti e Fioriti parecem considerar que algumas atitudes dos santos estavam muito além das das pessoas comuns para servirem de exemplo para elas. Talvez o modelo da santidade mencionado por Franciotti foi influenciado, ainda que de uma maneira parcial e contraditória, pela tradição antiga que via os santos como seres excepcionais e poderosos. Isso é, seres a serem venerados e invocados, mas não incentivados. Ao contrário, as palavras de Fioriti (escritas em 1752) parecem se referir à teoria acética do século XVIII, que dizia: "virtudes heróicas da santidade são rebaixadas ao

54 FRANCIOTTI, Cesare. Historia della Vita, e morte della Beata Sita. In: Historie delle miracolose imagini. Lucca: Guidoboni, 1613, p.421-429 (Vida), p.429-445 (considerações), p.435-436 (citações).

55 FIORITI, Bartolomeo. Vita, virtù, e miracoli di Santa Zita. Lucca: Marescandoli, 1752, p.XV, p.42-43. 
nível de 'prática' comum e do dia-a-dia (...) de 'qualquer tipo de pessoa'”. Em uma atmosfera tão cultural, o episódio da vida dos santos que não podia ser transformado em modelos de comportamento, às vezes era exposto aos seguidores mais para apreço do que para imitação". ${ }^{56}$

\section{Outros autores modificam completamente o conteúdo do Vida de Zita}

Os autores mencionados acima tentaram atualizar o conteúdo da Vida medieval, aumentando principalmente o corpo do texto original com detalhes, lições morais, reflexões e descrições das virtudes dos santos, explicados a partir dos deveres dos servos. Essas intervenções diminuem as diferenças entre o texto hagiográfico e os livros portáteis que apregoavam as condutas ideais. O autor desconhecido que publicou a Vida de Zita, em 1697, resumiu o Leitmotiv desses textos, que lidam com as obrigações dos servos. Ele afirmou que Zita se comportava "como se ela já houvesse absorvido o poder desse preceito, publicado por São Paulo, o apóstolo dos servos". Ela sabia que "aqueles que servem devem considerar seu mestre como o Ser Supremo, que é Deus, e então devem o obedecer e honrar de qualquer maneira possível". ${ }^{57}$ Entretanto, isso não é o suficiente para resolver o conflito existente na lenda medieval entre obediência e lealdade ao senhor na terra e obediência e lealdade ao Senhor no céu. Ao contrário, o conflito é enfatizado. É verdade que, quanto mais os autores consideravam Zita como uma serva, mais eles eram forçados a ficar do lado dos mestres quando Zita se esquecia de suas obrigações domésticas. Conseqüentemente, eles têm que explicar porque Deus vem ajudar a serva. Eles encontram uma explicação introduzindo pequenas distinções entre situações excepcionais e ordinárias, entre servos comuns e sagrados. Desse modo, contudo, eles reduzem (e algumas vezes negam) o valor exemplar da pessoa tomada como modelo.

Outros autores vão direto ao ponto fulcral original e modificam seu conteúdo completamente. Então, eles eliminam o conflito entre obediência ao mestre na terra e àquele no céu. Dessa maneira, não há mais necessidade de darem explicações vergonhosas. Em 1634, por exemplo, o nobre Pompeo Lommori publicou a Vida de Zita, apresentando uma versão da história que era muito diferente da lenda medieval: a serva nunca discorda de seus mestres. Os mestres mesmos são caridosos o bastante para permitirem que ela distribuísse seus bens. Para recompensar a bondade deles, Deus

56 ROSA, Mario. Prospero Lambertini tra 'regolata devozione' e mística visionaria. In: ZARRI, Gabriela. (ed.) Finzione e santità tra medioevo ed età modema, p.53. Sobre santos como seres excepcionais e poderosos ver VAUCHEZ, André. Santità.; para mais detalhes ver SARTI, Raffaella. Zita, serva e santa, p.314.

57 Vita di Santa Zita, p.6. 
dá a eles o privilegio de ter um santo na casa, isto é Zita. A multiplicação dos feijões é a intervenção de Deus a favor do mestre, não a favor de Zita. Os Fatinellis sabem que, atrás de um servo humilde, há um ser excepcional. Conseqüentemente, eles a tratam de uma maneira especial: eles pedem que os outros servos tomem conta do trabalho doméstico dela e que nunca ousem dar ordens a ela. Resumindo, não sobrou quase nada da identidade serva da santa. É verdade que o objetivo de Lommori não era educar os auxiliares domésticos. Ele estava se dirigindo a um público culto: ao contar o episódio caridoso da vida de Zita ele tinha como objetivo convencer os ricos a serem caridosos com os pobres. ${ }^{58}$

Em outras Vidas, a caridade dos mestres é enfatizada para ajustar a imagem de Zita à de uma serva leal e obediente. Como escreve o jesuíta Croiset, "ela nunca daria coisas sem permissão". Mais do que isso, ela considerava a propriedade que estava sob sua responsabilidade como "uma loja que ela tinha que prestar contas a Deus". E ela tinha tanto cuidado que seu mestre, ao perceber que "suas riquezas cresciam nas mãos [de Zita], dava permissão para que ela os distribuísse abundantemente aos pobres". ${ }^{59}$ A solução de Croiset ao conflito entre o mestre na terra e o Mestre no céu é combiná-los e remodelar a identidade de Zita de acordo com o protótipo de serva ideal. Essa solução põe todos os elementos em seu lugar de acordo com o ideal de hierarquia social estabelecido durante a Contra Reforma e parcialmente desenvolvido no período seguinte. Essa opinião irá prevalecer eventualmente nos próximos tempos.

\section{Massini, Zanzarri e Cianelli}

De meados do século XVIII até o começo do século XIX, a popularidade das Vidas da serva de Lucca declinou: eu não achei monografias da santa publicadas nesse período. Sua história, contudo, está incluída na segunda coleção das Vidas de santos, publicada em Roma, entre 1763 e 1767, pelo oratoriano Carlo Ignazio Massini. Ele foi acusado, corretamente ou não, de ser um jansenista. Como os jansenistas, ele sublinhou a função dos santos como exemplo. Ele descreveu Zita como uma serva modelo, precisa e leal. De acordo com a descrição de Massini, ela era caridosa: ela dava aos necessitados todos os seus pertences e intercedia por eles com seus mestres e outras pessoas piedosas. Contudo, o oratoriano não menciona a distribuição dos feijões. Ele também não menciona outros episódios da vida

58 LOMMORI, Pompeo. Vita e miracoli di Santa Sita. Lucca: Bidelli, 1634, p.34, 59-60, 36-37, 33. Sobre o objetivo de Lommori ver a dedicatória ao leitor: A' Lettori, (páginas não numeradas), p.34, 41-42. Ver também SARTI, Raffaella. Zita, serva e santa, p.340, notas de rodapé 93-94.

59 CROISET, Jean. Les vies des saints, p.536-537. 
dela que acabaram com um milagre. ${ }^{60}$ Massini não estava disposto a dar créditos às lendas da hagiografia medieval e teve cuidado ao lidar com os fenômenos místicos, as profecias e os milagres. Tal circunspeção, ocorrida provavelmente devido a sua adesão interna ao Jansenismo, assim como a sua insistência na função exemplar dos santos, era consoante com um tipo de devoção e de santidade sem exageros. Esse equilíbrio era defendido por diversos indivíduos, como o famoso historiador Ludovico Antonio Muratori e o Papa Benedito XIV. ${ }^{61}$ Apesar de todas as controvérsias, as Histórias Colecionadas, de Massini, foram publicadas várias vezes, e não apenas no século XVIII: longe do objetivo do autor, elas foram úteis ao longo do século XIX para a instrução política e religiosa das classes subordinadas. ${ }^{62}$ Objetos culturais diferentes foram revistos com esse objetivo. De fato, quanto mais pessoas aprendessem a ler, maior seria o público alcançado por meio de textos impressos. ${ }^{63}$

Nesse contexto cultural, há um aumento das Vidas de Zita ao longo desse século: "há tantas que seria impossível listá-los", escreveu Almerico Guerra, em $1875 .{ }^{64} \mathrm{O}$ ensinamento moral prevalece e molda a maioria deles. O retrato de Zita como uma serva perfeita é dado aos servos primeiramente como um "espelho" para imitarem. Por exemplo, em sua coleção Vite de Santi Che hanno servito..., Constantino Zanzarri percebeu que "a consciência dos servos é a que guarda nossos bens, cuida de nós quando dormimos, protege nossa reputação e defende nossa vida". Ele reescreveu a história de Zita citando a obra de Massini. Ele preferiu sua versão ao invés do texto medieval. É verdade, a Vida de Massini era mais adequada a um livro século XIX, que tinha como objetivo dar "apoio e exemplo" aos serviçais. ${ }^{65}$ Ao contrário, a versão medieval estaria certamente fora de lugar em um livro como esse. Nesse período, serviçais que pensassem que era "melhor servir a Deus do que ao homem" incitariam apenas raiva e irritação. ${ }^{66}$ Mais do que isso, a ideologia da propriedade privada como um direito natural e intocável

60 MASSINI, Carlo Ignazio. Raccolta di vite de' santi. Roma: Pagliarini, 1763; MASSINI, Carlo Ignazio. Seconda raccolta di vite de' santi. Venezia: Ferrarin, 1789, vol.5, p.09-217 para a Vida de Zita. Sobre Massini ver STELLA, Pietro. Gianseismo e agiografia in Itália tra '700 e '800. Salesianum, vol.42, p.835-853, 1980; STELLA, Pietro. Le 'vies des saints' di Adrien Baillet: diffusione e recezione in área italiana. In: BOESCH GAJANO, Sofia. (ed.) Raccolte di vite di santi dal XIII al XVIII secolo. Strutture, messagi, fruizioni. Fazano di Brindisi : Schena, 1990, p.231-233.

61 STELLA, Pietro. Gianseismo e agiografia in Itália tra '700 e '800; Rosa 1981, 1988, 1991.

62 STELLA, Pietro. Gianseismo e agiografia in Itália tra '700 e '800, p.836, 849-850; SARTI, Raffaella. Zita, serva e santa, p.341, nota de rodapé 104. Sobre a instilação religiosa e política das classes mais baixas ver GINZBURG, Carlo. Folklore, magia, religione, p.663; ALLEGRA, Luciano. II parroco: um mediatore fra alta e bassa cultura. In: VIVANTI, Corrado. Storia d'Italia. Annali 4, p.941; CAFFIERO, Marina. Religione e modernità in Itália (secoli XVII-XIX).

63 Sobre livros do século XIX para servos ver CASALINI, Maria. Servitú, nobili e borghesi nella Firenze dell'Ottocento.

64 GUERRA, Almerico. Istoria della vita di Santa Zita. Lucca: S. Paolino, 1875, p.19 e 276-278.

65 ZANZARRI, Constantino. Vite de' Santi che hanno senvito in qualità di famigliari narrate a conforto ed esempio di coloro che disimpegnano eguali uffici. Roma: Tipografia Tiberina, 1868, p.5-6 e 221-229, 1868.

66 Ver por exemplo Manuale completo per la gente di senvizio. Milano: Sanvito,1879, p.25 (esse livro foi parcialmente copiado de CELNART, Mme [dame Bayle-Mouillard Canard]. Manuel complet des domestiques. Paris: Librarie Encyclopédique, 1836). 
era mais forte do que nunca. ${ }^{67}$ Era tão forte que um autor, explicando aos serviçais que tinham que respeitar a propriedade de seus mestres, não mencionou exceções à regra. Ele também não mencionou casos de extrema necessidade. ${ }^{68}$ Diferentemente do hagiógrafo medieval, tanto Massini e Croiset descreveram Zita como uma serva que nunca negligenciou sua tarefa de lealdade. Zanzarri escolheu a versão de Massini provavelmente porque ela oferecia duas vantagens em comparação com a versão de Croiset. De um lado não mencionava os milagres da santa, que poderiam ser mal entendidos mesmo se revisados. Do outro lado, a história acabava com uma lista de citações populares de São Paulo, seguida por uma série de "tarefas específicas dos servos", que se encaixavam perfeitamente em um livro com o objetivo de educar a "equipe doméstica". ${ }^{69}$

Filippo Cianelli, que escreveu duas Vidas de Zita, não se dirigiu aos serviçais especificamente como havia feito Zanzarri. Contudo, assim como Zanzarri, ele destacou o exemplo dela aos servos e particularmente às servas. Seu "excelente" e providencial exemplo ia persuadi-los a prestarem atenção em Deus, a serem humildes e leais e a amarem o trabalho. Além disso, como uma santa aceitou passivamente as perseguições permitidas por Deus com o objetivo de testar sua virtude, do mesmo modo servos tinham que pacientemente suportar todos os abusos e erros de outros servos e de seus mestres. "Aqueles que são perseguidos injustamente terão conforto", ele escreveu. "Deus nos dá problemas para testar nossa lealdade. Não são os seres humanos que conspiram contra nós, mas Deus em Si mesmo que, graciosamente, vem até nós através [dos problemas] porque Ele nos ama. Todos os santos são aflitos e oprimidos. Que nós aproveitemos a oportunidade que nos é dada seguindo o exemplo dela". ${ }^{70}$

Afirmações similares, que podem ser encontradas nas versões muito mais antigas das Vidas de Zita, foram repetida por todos os autores do século XIX mencionados. Nesse período, aos servos acusados de serem imprudentes, impacientes e insubordinados era mostrado o retrato de um santo exemplar, paciente e subordinado. Mais do que isso, se o servo tinha que apoiar seu mestre, o súdito tinha que apoiar seu soberano: São Paulo, alguém observou, havia prometido "uma grande recompensa do céu para aqueles que, como Jesus Cristo, tolerassem pacientemente as ofensas de seus governantes". ${ }^{71}$

67 FRIEDMANN, W.G. Property. In: WIENER, Ph. P. Dictionary of the History of ideas. Studies of selected pivotal ideas. New York: Charles Scribner's sons, 1973, v.3, p.654.

68 PATIS, Georg. Zita, di hl. Dienstmagd. Innsbruck: Aufschager, 1858

69 MASSINI, Carlo Ignazio. Seconda raccolta di vite de' santi, vol.5, p.216-217; ZANZARRI, Constantino. Vite de' Santi che hanno servito in qualità di famigliari..., p.228-229.

70 CIANELLI, Filippo. Breve ragguaglio delle gesta, e de' miracoli di Santa Zita. Venezia: se.,1804, p.11, 63, 16-17, 30-32 (citação) e CIANELLI, Filippo. Ragguaglio delle gesta, e dei miracoli di Santa Zita. Lucca: Bertini, 1826, p.19, 130, 29-31, 62-64, 65 (citação).

71 REGGIANI, Flores. 'Um problema técnico e um problema morale': la crisi delle domestiche (Milano, 1890-1910). In: MARCHETI, Ada Gigli, torcellan, Nanda. (eds.) Donna lombarda. 1860-1945. Milano: Angeli, 1992; e CASALINI, 


\section{Patis, Montreuil e Guerra}

No século XIX, os católicos se preocupavam com o inconformismo das classes mais baixas. Eles também observaram, com o espírito perturbado, que "o egoísmo quebrava todos os laços de benevolência entre mestres e servos, laços esses que foram tão fortes no passado". Foi sublinhado que muitos superiores "preocupavam-se pouco ou nada" com a conduta de seus subordinados, das quais eles eram responsáveis perante Deus. ${ }^{72}$ Então, para a Igreja Católica, restaurar o passado contra as novidades satânicas do presente também significava guiar os superiores a reassumir a benevolência para com seus subordinados. ${ }^{73} \mathrm{~A}$ história de Zita podia oferecer uma lição moral aos senhores também: eles serão ensinados a amar seus servos domésticos e permitir que sejam caridosos. ${ }^{74}$

A necessidade de contribuir para a "reforma limpadora" da relação entre senhores e serviçais fez com que o jesuíta Georg Patis escrevesse uma Vida da santa. Com essa Vida ele proveria a ambos com um sumário das "obrigações mútuas e trocas estabelecidas pelo Cristianismo". Alfred-Marie de Montreuil tinha um propósito maior quando descreveu a grandeza de Zita: para acordar nos ricos o sentimento de irmandade para com a "classe sofredora da sociedade" e, ao mesmo tempo, dar conforto, encorajar e educar "os pequenos e fracos". O projeto de restauração que Almerico Guerra queria fazer também era igualmente grande. Em sua opinião, eram necessários novos e poderosos santos para a religião ganhar novamente "seu legítimo domínio sobre o mundo" e para "a face da terra" se renovar. Mas como "surgiriam" essas figuras? De acordo com Guerra, "após o poder supernatural da graça", apenas hagiógrafos poderiam contribuir para a "moldagem" de novos santos: é por isso que ele contou a história de Zita. ${ }^{75}$

O objetivo dos três autores - Patis, Montreuil e Guerra - era contribuir com a restauração católica. Contudo, os resultados foram diferentes. Ao encontrar inspiração na história de Zita, Patis escreveu um tipo de "novela piedosa". Montreuil e Guerra, ao contrário, tinham como objetivo serem "verdadeiros especialistas sobre a santa" ${ }^{76}$ Os trabalhos dos dois últimos tinham como objetivo colocar de volta a história dela no contexto do século

Maria. Senitú, nobili e borghesi nella Firenze dell'Ottocento (acusações aos servos); I fasti della chiesa nelle vite de' Santi. Milano: Bonfati, 1826, vol.4, p.12 (citação).

72 [MONTANARI ANTONIO]. Della responsablità, vigilanza e carità dei ricchi verso i famigli e dei capi di bottega o di fondachi verso i subalterni e gli operai. Giomale ecclesiastico di Bologna, v.2, p.208, 1841

73 GINZBURG, Carlo. Folklore, magia, religione, p.665-668; BOLGIANI, Franco. Chiesa e società moderna: il problema della scristianizzazione. In: TRANFAGLIA, Nicola, FIRPO, Massimo. (eds.) La Storia: i grand problemi dal Medioevo all'eta contemporanea. Torino: Utet, 1988; Traniello 1988, v.7, part.2, p.733-794; CAFFIERO, Marina. Religione e modernità in Itália (secoli XVII-XIX).

74 FABI MONTANI, Francesco. Santa Zita vergine lucchese. In: Perfetto leggendario. Roma: Minerva, 1841, p.220.

75 PATIS, Georg. Zita, di hl. Dienstmagd, p.5; MONTREUIL, Alfred-Marie de. Vie de Sainte Zite. Paris: Waille, 1843, p.XXXV-XXXVl; GUERRA, Almerico. Istoria della vita di Santa Zita, p.5-10.

76 GUERRA, Almerico. Istoria della vita di Santa Zita, p.19-21. PATIS, Georg. Zita, di hl. Dienstmagd, p.19. Esse autor apresenta seu livro como uma "novela piedosa. 
XIII e por isso ostentavam notas de rodapé, faziam uso de fontes primárias, entre outros. Inicialmente, eles eram mais apropriados ao leitor culto e, apenas mais tarde, foram popularizados. Entre as Vidas do século XIX, essas duas continuam de várias maneiras as mais próximas do "original". Tomaremos como exemplo o episódio dos feijões.

Todos os escritores analisados previamente, exceto Montreuil e Guerra, evitam mencionar o episódio, ou o reescrevem de acordo com a versão que mostra Zita como uma serva perfeita. ${ }^{77}$ Seguindo uma tradição estabelecida, tanto Montreuil como Guerra afirmaram que os Fatinellis aprovaram a doação de esmolas de Zita. Porém, mais tarde, eles admitiram que ela havia distribuído os feijões aos famintos sem permissão: para o bem dos pobres ela seria culpada e punida por seus mestres. ${ }^{78}$ Não é fácil distinguir se a escolha deles ocorre devido a seus escrúpulos filológicos, a tentativa de fazer com que os ricos tivessem compaixão pelos pobres ou a percepção de que apenas poucos servos iriam ler seus livros. Contudo, é fato que, quando essa diretriz muda, eles tomam as precações necessárias, como no caso da versão popularizada da Vida, de Guerra. Em sua conclusão, o autor impulsiona as garotas, principalmente servas, a seguirem o exemplo da santa.

Quando se trata de doações de esmolas [- ele adiciona -] lembrem-se que Zita teve permissão de seus mestres para distribuir seus bens; e se, às vezes, ela ia longe demais era porque ela agia sob impulso divino, suportada por maravilhosos milagres. A não ser que o mesmo aconteça com as nossas servas, elas devem dar aos necessitados apenas o que Ihes for permitido pelos seus mestres.

A não ser por isso, as servas deveriam imitar a santa em todos seus trabalhos. Na verdade, Deus a "escolheu como um exemplo especial para elas". ${ }^{79}$

\section{Zita como um modelo específico para as servas}

A imagem de Zita como um modelo específico para as servas é particularmente popular no século XIX, mesmo que isso possa ter ocorrido também nos séculos anteriores. ${ }^{80}$ Sem dúvida isso decorria do fato de que uma notável feminização dos servos domésticos teve lugar ao longo desse

77 SARTI, Raffaella. Zita, serva e santa, p.344-345, nota de rodapé 135

78 MONTREUIL, Alfred-Marie de. Vie de Sainte Zite, p.108-111; GUERRA, Almerico. Istoria della vita di Santa Zita, p.156-158. Para mais detalhes ver SARTI, Raffaella. Zita, serva e santa, p.345, nota de rodapé 137

79 GUERRA, Almerico. Compendio della vita di Santa Zita. Lucca: S. Paolino 1878, p.92-94.

80 RAYNAUD, Theophile. Hagiologium Lugdunense. Lugduni: Sumt. Horatii Boissat \& Georgii Remeus, 1665, p.568; FONTANA, Aldigherio. La santità, e la pietà triunfante, part.2, p.87; FIORITI, Bartolomeo. Vita, virtù, e miracoli di Santa Zita, p.15; CIANELLI, Filippo. Breve ragguaglio delle gesta, e de' miracoli di Santa Zita, p.11; CIANELLI, Filippo. Ragguaglio delle gesta, e dei miracoli di Santa Zita, p.19; PATIS, Georg. Zita, di hl. Dienstmagd; GUERRA, Almerico. Istoria della vita di Santa Zita, p.92; e GUERRA, Almerico. Compendio della vita di Santa Zita, p.278. 
século. Contudo, não pode ser descartado que tal especialização da função exemplar da santa também correspondia ao interesse crescente do clero em relação às mulheres. ${ }^{81} \mathrm{Na}$ verdade, uma precondição essencial para continuar com qualquer projeto de restauração moral e religiosa era manter as mulheres dedicadas à sua fé (e à condição de subordinadas), já que a secularização afetava predominantemente os homens.

Dessa maneira é possível interpretar não apenas o propósito de indicar modelos específicos para as mulheres, mas também o desenvolvimento ao mesmo tempo de estruturas de relaxamento e controle da ordem. Muitos institutos "para servas" foram nomeados Santa Zita: nesses abrigos "jovens garotas pobres e inocentes" seriam ensinadas "como serem [boas] servas" e seriam enviadas a famílias que poderiam guardar a "inocência" delas. Havia um duplo propósito: tomar conta do "espírito e riqueza material" das empregadas e "ajudar no controle e conduta moral das famílias" que as garotas serviam. ${ }^{82}$ Nos séculos XIX e XX, associações e outras instituições para os serviçais e criados também foram nomeadas de Santa Zita. ${ }^{83}$

Essas instituições, é claro, promoviam a adoração de Zita. Isso ajudou a manter a imagem da santa como um exemplo específico para as criadas, tal como era disseminado nos livros para serviçais dos séculos XIX e XX. ${ }^{84}$ Mas também reforçava a crença de que Zita era a guardiã especial delas, deixando mais forte a representação de Zita como protetora das domésticas ${ }^{85} \mathrm{~A}$ partir das últimas décadas do século XIX e, mais vigorosamente, durante o século XX, a Igreja adotou uma política promocional para os "patrões morais". ${ }^{86}$ Essa política também envolvia Zita. Na verdade, no dia 11

81 Sobre o processo de feminização do Catolicismo ver BOLGIANI, Franco. Chiesa e società moderna, p.748; DI CORI, Paola. Rosso e bianco. La devozione al Sacro Cuore di Gesù nel primo dopoguerra. Memoria, n.5, p.82-107, 1982; SCARAFFIA, Lucetta. La santa degli impossibili. Vicende e significati della devozione a S. Rita. Torino: Rosemberg \& Sellier, 1990, p.11, 51-58, 91-94; SCARAFFIA, Lucetta. II Cristianesimo l'há fatta libera, collocandola nella famiglia accanto all'uomo' (dal 1850 alla 'Mulieris dignitatem'). In: SCARAFFIA, Lucetta, ZARRI, Gabriela. (eds.) Donne e fede, 1994, p.440-493; DE GIORGIO, Michela. II modelo cattolico. In: DUBY, Georges, perrot, Michelle. Storia delle donne in Ocidente. Roma/Bari: Laterza, 1991, v.4 (L'Ottocento), p.157-159; CAFFIERO, Marina. Dall'esplosione mistica tardo-barroca all'apostolato sociale. In: SCARAFFIA, Lucetta, ZARRI, Gabriela. (eds.) Donne e fede; e CAFFIERO, Marina. Religione e modernità in Itália (secoli XVII-XIX), p.113-189; SARTI, Raffaella. Zita, serva e santa, p.320-321, p.346-347, notas de rodapé 144-148.

82 GUERRA, Almerico. Istoria della vita di Santa Zita, p.267-276.

83 GUERRA, Almerico. Istoria della vita di Santa Zita, p. 167-176; CASALI, Giuseppe. Santa Zita. Lucca: Ecco di S. Marco, 1936, p.68; PUCCINELLI, Pellegrino. Santa Zita nella devozione universale delle domestiche e delle lavoratrici della casa. Lucca: Artigianelli, 1954, p.8-14; CRIPPA, Ermínio. Le sante del sostro lavoro. Naopli: Messis, 1961; LEONI, Diego. Lettere delle 'sorelle' dell'Opera di S. Zita, s.d. (mimeo.) - Sou grata a Diego Leoni por enviar essa comunicação não publicada).

84 Ver nota de rodapé 79 e BELLOLI, Giovanni. II famulato cristiano. Bergamo: S. Alessandro, 1935, p.142-144, 158161, 202-204; PELOSO, Luigi. Domestiche e infermiere. Arzignano: Dal Molin, 1937, p.81, 86; GALLIA, Maria. Servire com amore. Milano: Vita e pensiero, 1939; MAZZEL, Massimiliano. Ancilla domini. Alba: Pia Società S. Paolo, 1943, p.9, 11, 14, 130, 138. Nesses livros o milagre dos feijões não é mencionado. Ver SARTI, Raffaella. Zita, serva e santa, p.349, nota de rodapé 167 .

85 GUERRA, Almerico. Istoria della vita di Santa Zita, p.267; CASALI, Giuseppe. Santa Zita, p.68; PELOSO, Luigi. Domestiche e infermiere, p.83-86; BELLOLI, Giovanni. II famulato cristiano, p.261-266; MAZZEL, Massimiliano. Ancilla domini, p.14 e 28-31; PUCCINELLI, Pellegrino. Santa Zita ... Lucca: La Tipografica di O. \& E. Malanima,1949, p.148; PUCCINELLI, Pellegrino. Santa Zita nella devozione universale delle domestiche e delle lavoratrici della casa, p.8, 15.

86 BUGNINI, Annibale. Patrono. In: In: Enciclopedia Cattolica, 1952, col.988; CORTESINI, D. De coelestibus Patronis. Monitor ecclesiasticus, v.7, n.88, p.81-115, 1963 
de março de 1955, o Papa Pio XII proclamou Zita "santa protetora universal das servas". Em um mundo que corria o risco da secularização, a questão não era apenas dar aos serviçais um exemplo de "humildade, obediência, conduta correta e paciência Cristã" (paciência era uma virtude que o Papa insistia em defender), mas "garantir proteção de Cima" para mulheres que "estavam mais e mais em perigo". Além disso, pretendia disponibilizar "uma protetora em quem as pessoas em apuros poderiam confiar e contar", particularmente quando era necessário guardar as virtudes e a fé que poderiam ser solapadas pelos próprios patrões. Apenas dessa maneira poderia a boa serviçal, como uma missionária, colaborar na proteção e na disseminação dos bons valores cristãos. ${ }^{87}$

A decisão do Papa foi estimulada por uma petição subscrita por muitos indivíduos que pertenciam a ordens religiosas e ao clero secular, e por miIhares de empregados domésticos e devotos da santa. De acordo com um relatório, publicado em uma coletânea que apareceu em Lucca, em 1978 , quando se celebrava o oitavo centenário da morte de Zita, empregadas domésticas e fiéis brasileiros desempenharam um papel crucial nesse episódio. Graças à O bra Santa Zita (uma congregação de freiras que teve início em Higienópolis, um bairro de São Paulo, que foi oficialmente reconhecida em 1944 e ereta em 1950 pelo arcebispo de São Paulo), 32 bispos e 16.000 fiéis brasileiros subscreveram a petição enviada ao Papa com o intuito de proclamar Zita como patrona dos empregados domésticos. ${ }^{88}$

\section{A feminização da função exemplar de Zita sob a luz da feminiza- ção do serviço doméstico}

O fato de que Zita era uma serviçal nem sempre teve a mesma importância. Para o primeiro hagiógrafo, ela era primeiramente e mais importante uma mulher sagrada a ser imitada pelas pessoas do clero e pelos leigos; para os habitantes de Lucca uma santa do panteão local, para os espanhóis uma santa que protegia as mulheres durante o parto... A todo momento, cruzamos com narrativas que dão ênfase a este ou àquele aspecto da identidade de Zita. No entanto, o fato de que ela era uma serviçal se apresentava cada vez mais como a característica central de sua identidade. ${ }^{89}$ Mais do que isso, mais ou menos a partir do início do século XIX, o fato dela ser uma mulher serviçal e principalmente um modelo a ser imitado que servisse às mulheres serviçais foi particularmente enfatizado. De maneira crescente, ela se tornou a santa das mulheres serviçais.

87 Acta Apostolicae Sedis, 58, s.2, 1956, p.259-260; CASALI, Giuseppe. Santa Zita patrona delle collaboratrici familiari. Lucca: Regnum Christi, 1965, p.7-8; Santa Zita gloria di Lucca. Lucca: Nuova Grafica Lucchese, [1978], p.4.

88 Santa Zita Gloria di Lucca, p. 5. A Obra Santa Zita ainda existe; ver http://www.catolicanet $\mathrm{com} /$ ?system $=$ igreja\&action $=$ casa residencia ver\&id $=7701$

89 SARTI, Raffaella. Zita, serva e santa, p.322-327. 
Como já foi sugerido anteriormente, essa mudança ocorreu, de um lado, por causa do aumento da atenção que a Igreja passou a dispensar à educação feminina; de outro lado, refletia claramente a feminização do serviço doméstico que estava ocorrendo. De fato, a passagem do Antigo Regime à modernidade foi caracterizada pela feminização do serviço doméstico. Diversos autores têm opiniões diversas sobre o início dessa mudança, parcialmente porque nem todos usam a mesma definição de serviçal, parcialmente porque eles focam contextos diferentes. De qualquer maneira, os dados disponíveis mostram que, na sociedade pré-industrial, as mulheres representavam de $40 \%$ a $80-90 \%$ dos empregados domésticos (em algumas cidades no final do século XVIII), enquanto que, após 1850, elas normalmente representavam de $70 \%$ a $98 \% .{ }^{90}$

Claro que seria enganoso comparar sociedades tradicionais e modernas se as transformações das taxas de razão de sexo dos serviçais fossem interpretadas do ponto de vista teológico. Em primeiro lugar, o número de mulheres entre os serviçais não somente aumentou durante a passagem para a modernidade. Houve longas e curtas oscilações ao longo dos séculos. Em Florença, no último quartel do século XIV, as mulheres representavam apenas $37 \%$ dos serviçais. Entre 1400 e 1450, seu número aumentou para $65 \%$, alcançando $78 \%$ no final do século. Mas, no século XVI, se seguiu uma diminuição no número de serviçais, o que continuou entre os séculos XVII e XVIII. Em Veneza provavelmente também a proporção de mulheres entre os serviçais tenha diminuído entre o século XVI e o final do século XVIII. Em segundo lugar, o serviço doméstico não se tornou (ou foi) uma ocupação completamente feminizada em todos os lugares do mundo, ao longo dos séculos XIX e XX, como foi apontado por Karen Tranberg Hansen, em seu estudo sobre a Zâmbia, onde os empregados domésticos são em sua maioria homens. Finalmente, podemos observar que a razão entre os sexos dos serviçais ainda está mudando: a Itália, por exemplo, passou por uma re-masculinização do serviço doméstico nas décadas recentes, devido, em parte, ao aumento de imigrantes em ocupações domésticas, entre os quais os homens são numerosos. Nesse sentido, cada mudança de gênero na composição da equipe doméstica deve ser interpretada no contexto em que ela acontece. No século XV, a "era do ouro" florentina para as mulheresserviçais provavelmente ocorreu devido às conseqüências demográficas da Peste Negra, de 1348, e a masculinização dos serviçais de Veneza no século XVI teve a ver com a aristocratização da sociedade local. ${ }^{91}$

90 Referências sobre a rica literatura sobre a feminização dos servos, ver SARTI, Raffaella. Notes on the feminization of domestic service. Bologna as a case study (18 $18^{\text {th }}-19^{\text {th }}$ centuries). In: FAUVE-CHAMOUX, Antoinette, FIALOVÁ, Ludmila. (eds.) Le phénomène de la domesticité em Europe, XVle-Xxe siècles. Praha : Ceská Demografická Sociologický Ústav av CR,1997, p.125-163.

91 Sobre Florença: KLAPISCH-ZUBER, Christiane. Women servants in Florence (14th-15th centuries). In: HANAWALT, Barbara. (ed.) Women and work in Preindustrial Europe. Bloomington: Indiana University Press, 1986, p.56-80; Sobre Veneza: ROMANO, Dennis. Housecraft and statecraft. Domestic Service in Renaissance Venice, 1400-1600. 
Nos séculos XIX e XX, a feminização não era conseqüência de um processo único, mas sim resultado de vários processos que afetavam a oferta e a demanda de serviçais e influenciava de maneiras diferentes tipos distintos de serviçais: a diminuição do padrão aristocrático de contratação de serviçais, que se caracterizava por uma equipe grande e predominantemente masculina; o desaparecimento de algumas funções executadas por homens (por exemplo, a função de carregadores de cadeiras); a migração de algumas funções para a esfera extra-doméstica (como, por exemplo, a função de contabilidade); a emergência dos burgueses como os maiores patrões de serviçais (a classe média sempre preferiu domésticas mulheres); a nova ênfase na casa e na família como o reino da mulher; a fuga dos homens dessa ocupação por causa dos ataques dos revolucionários que diziam que esse serviço não era digno de um cidadão livre e o desenvolvimento de outras alternativas de emprego disponíveis mais aos homens do que às mulheres; o aumento da oferta de mulheres serviçais devido à migração do interior para os centros rurais e assim por diante. Algumas mudanças favoreceram a crescente importância das criadas dentro da esfera dos empregados domésticos por meio de um processo de "subtração" e "desmasculizaçao"; ou de "substituição" dos homens pelas mulheres (como no caso dos cozinheiros); ou ainda da "adição" de serviçais-mulheres encarregadas de tarefas tradicionais ou novas. ${ }^{92}$

Contudo, no que diz respeito à feminização do serviço doméstico, alguns pontos podem ser enfatizados. Claramente, o fato de que as Vidas de Zita foram cada vez mais direcionadas às mulheres-serviçais refletia e dava mais força à feminização do status servil. Essa feminização não foi um processo neutro em termos do valor atribuído ao serviço doméstico. Na verdade, a feminização ocorrida durante os séculos XIX e XX coincidiu com uma crescente estigmatização do status servil. Sem dúvida, no início da era moderna, ser um servo era uma condição negativa. Mas havia mais ambigüidades do que nos séculos seguintes. Como sugerido anteriormente, hierarquia, dependência e obrigação estruturavam todas as sociedades do Antigo Regime, não apenas as relações domésticas. Então era "normal" estar envolvido em relações assimétricas. Além disso, é geralmente enfatizado que relações assimétricas ofereciam a oportunidade de estar em contato com pessoas de um escalão superior, de ter um mestre que protegeria seus servos. "Nem todos os tipos de servidão são desonradas e

Baltimore/London: the Johns Hopkins University Press, 1996; p.XXI, 229-230; Zâmbia: HANSEN TRANBERG, Karen. Distant companions: servants and employers in Zambia 1900-1985. Ithaca: Cornell U.P., 1989; La presenza straniera in Italia negli anni '90. Informazioni, n.61, Roma: Istat, 1998, p.71-87, 464; SARTI, Raffaella. Servire al femminile, servire al maschile nella Bologna sette-ottocentesca. In: NAVA, Paola. (ed.) Comuni di Carpi, Operaie, serve, maestre, impiegate. Torino: Rosemberg \& Sellier,1992; SARTI, Raffaella. Quali diritti per la donna? Servizio domestico e condizione femminile dalla rivoluzione francese ad oggi. In: PALAZZI, Maura, SOLDANI, Simonetta. (eds.) Lavoratrici e cittadine nell'Italia contemporanea. Torino: Rosemberg \& Sellier, 2000.

92 SARTI, Raffaella. Notes on the feminization of domestic service; SARTI, Raffaella. Quali diritti per la donna? 
calamitosas" [disdic evoli e calamitose], escreveu, por exemplo, um autor no final do século XVII. Na sua opinião, servir um príncipe geralmente deveria ser considerado "um grande benefício do paraíso" [um gran benefizio di paradiso]. Finalmente, tornar-se um servo era um grande meio de conseguir uma família e uma casa para órfãos ou outras pessoas sem laços familiares fortes ou "normais", como aponta Giulia Calvi. Ao contrário, a crescente ênfase na liberdade e igualdade, graças inicialmente ao lluminismo e à Revolução Francesa, trouxe uma desvalorização da dependência e estigmatizou mais ainda a condição dos serviçais. Essas mudanças contribuem para explicar a ênfase na paciência com que nos deparamos nas Vidas de Zita, escritas nos séculos XIX e XX: ser um serviçal tornou-se um status mais estigmatizado e era necessário mais paciência para aceitá-lo. ${ }^{93}$

Esse estigma mais forte deve ser contado, na minha opinião, entre as razões que explicam a fuga do homem - principalmente homens da classe média, como era a regra no caso de contadores, secretários, etc. - do serviço doméstico, um processo que também piorava o status social dos serviçais. Além disso, a fuga dos homens era um dos numerosos fatores tanto da diminuição da antigamente grande e complexa equipe de domésticos, como da diminuição do número de pessoas que poderiam ser descritas (de um maneira ou de outra) como serviçais. A categoria social e cultural de serviçal que, por muito tempo, foi disseminada e multifacetada, passou a ser marginalizada. A feminização, o estigma, a marginalização e a piora do status social tornaram-se um único fenômeno: ser um serviçal tornou-se uma condição tipicamente feminina e, ao mesmo tempo, uma ocupação mais desprezada, cada vez mais executada por mulheres das classes baixas ou de origem rural.

Essa transformação refletiu e reforçou a idéia de que dependência era algo especificamente feminino (assim como infantil). Então isso também afetou a construção das identidades de gêneros (sobre esse tema, vale apenas registrar que as mulheres, bem como os serviçais foram excluídos dos direitos de cidadania durante a Revolução Francesa) ${ }^{94}$ Não é surpreendente então, que alguém afirmasse que Zita - a Zita das narrativas mais recentes - "praticava as virtudes que deveriam ser comuns a todas as mulheres". ${ }^{95}$ Também não é surpreendente, que o serviço doméstico tornou-se uma ocupação vergonhosa para as mulheres que trabalhavam como serviçais, assim como exemplifica Pothiti Hantzaroula..$^{96}$

93 SARTI, Raffaella. Quali diritti per la donna?; ROSSI, Pio. Convito morale...., vol.2, p.380-381.

94 ROSANVALLON, Pierre. Le sacre du citoyen. Du suffrage universel en France. Paris : Gallimard, 1992 ; SARTI, Raffaella. Quali diritti per la donna?

95 [MORETTI, Elena Amico]. Zita di Lucca, domestica santa. L'O bservatore Romano, v.22, p.4, 23/5/1950. ver também Bruni 1966; FENOCCHIO, Giuseppe. Fu autentica missione di donna la sua vita. In: Santa Zita gloria di Lucca, p.6

96 HANTZAROULA, Pothiti. Vergonha nas Narrativas sobre Servos Domésticos na Grécia (1922-1945) (texto mimeo.) 
De qualquer modo, não devemos nos esquecer que existiam (e ainda existem) mulheres que consideram o serviço doméstico como uma maneira de conseguir melhores condições materiais, liberdade e independência, não apenas após a morte - como Zita, serva na terra, amante no céu - 97 mas também durante suas vidas. Esse foi o caso de muitas mulheres que, ao entrarem no serviço doméstico, escaparam da pobreza e da indigência, apesar desse ser um caminho doloroso. ${ }^{98}$ Não há dúvida que ainda hoje, período caracterizado pela globalização do mercado de trabalho doméstico, muitas mulheres deixam suas famílias e seus países para se tornarem serviçais, com a esperança de assim melhorarem suas vidas. "Ninguém deixa sua casa se não para melhorar de vida", explicou uma mulher caribenha que entrevistei há alguns anos atrás, que trabalhava como doméstica em Florença. ${ }^{99}$ Hoje em dia, algumas dessas mulheres acham trabalho por meio de agências que oferecem empregadas pela Internet ${ }^{100}$ - um lugar virtual onde as mulheres de países (cada vez mais) pobres e patrões (cada vez mais) ricos podem se encontrar. Eis uma mistura estranha de mídia moderna, relações assimétricas arcaicas e novas desigualdades mundiais. Mas é também na Internet - em uma fusão bizarra de passado e futuro - que se pode achar cerca de 3.400 web-sites em inglês contando a história de Zita (esse número cresce para cerca de 50.000 se a pesquisa é realizada em português)..$^{101}$

97 Acta Apostolicae Sedis, 58, s.2, 1956, p.259-260

98 Por exemplo Per vito e per vestito (sulle condizioni di vita e lavoro delle donne di senvizio trentine. Corsi sperimentali per lavoratori. Rovereto, 1980-81, passim.

99 R.R., Fevereiro 2000.

100 LUTZ, Helma. At your service madam! Domestic service old and new. Gender, class, ethnicity and profession. Third European Social Science History Conference. Amsterdam, 12-15 April, 2000. Eu agradeço Helma Lutz por me mandar seu paper ainda não publicado (ver agora www.vifu.de).

101 Os textos publicados nos web-sites representam uma fonte para pesquisas mais profundas sobre maneiras de contar a história de Zita. 